Note

\section{Production of Characteristic Odors by Neurospora}

\author{
Hiromasa Yamauchi, Takaji Obata, \\ Teruo AMACHI and Shodo HaRa \\ National Research Institute of Brewing, \\ 2-6-30 Takinogawa, Kita-ku, Tokyo 114, Japan \\ * Laboratory of Microbial Science, Institute for Fundamental \\ Research, Suntory Ltd., Mishima-gun, \\ Osaka 618, Japan
}

Received June 5, 1991

We reported that Neurospora sp. ATCC 46892 produced a fruity odor, for which ethyl caproate may be responsible, ${ }^{1}$ but few studies have been done on odor production by other Neurospora strains. This study was aimed at examining the production of odors by several Neurospora strains.

We examined 12 Neurospora strains, including the ATCC 46892 dscribed previously. ${ }^{1)}$ Neurospora sp. T, which was newly isolated from beiju, a fermented food in Brazil, had been obtained from Dr. Satoh (Universidade Estadual de Campinas, Brazil) and was classified by us from its morphological characteristics. Other strains were purchased from the Institute for Fermentation, Osaka, Japan.

These Neurospora strains were inoculated into $5 \%$ malt broth and grown aerobically at $30^{\circ} \mathrm{C}$ for several days in a $500-\mathrm{ml}$ shaking flask. Then each culture was filtered through Miracloth (Calbiochem Corp.) or a microfilter $(0.45 \mu \mathrm{m})$.

Volatiles were extracted and analyzed. Two hundred and fifty $\mathrm{ml}$ of the filtrate obtained was saturated with $\mathrm{NaCl}$ and then $125 \mathrm{ml}$ of ethyl acetate containing an internal standard, methyl caproate, was added to extract volatiles. After the mixture was shaken vigorously for one minute by a Mini-Beadbeater (Biospec Products), four microliters of the extract was analyzed by GC or GC-MS.

GC was done with a Perkin-Elmer 8320 B capillary gas chromatograph. The conditions were the same as described elsewhere ${ }^{3)}$ with some modifications: column, a bonded fused silica capillary column, $15 \mathrm{~m}, 0.53 \mathrm{~mm}$ i.d., film thickness $=1.0 \mu \mathrm{m}$; stationary phase, DB-WAX from $J$ and $W$ Scientfic Inc.; carrier gas, helium at $4.6 \mathrm{~m} / / \mathrm{min}$ (split ratio $=1 / 5$ ); column temperature, kept at $70^{\circ} \mathrm{C}$ for $3 \mathrm{~min}$, raised from $70^{\circ} \mathrm{C}$ to $100^{\circ} \mathrm{C}$ at the rate of $10^{\circ} \mathrm{C}$ per $\min$, from $100^{\circ} \mathrm{C}$ to $230^{\circ} \mathrm{C}$ at the rate of $20^{\circ} \mathrm{C}$ per min and then kept at $230^{\circ} \mathrm{C}$ for $7.5 \mathrm{~min}$; injection port and detector temperature $250^{\circ} \mathrm{C}$.

GC-MS was done with a Hewlett Packard 5970B GCMS System. The conditions of gas chromatography were
Table I. ODOR FORMATION BY VARTOUS Neurospora StRaIns

The experimental details are given in the text.

\begin{tabular}{lc}
\hline \multicolumn{1}{c}{ Strain } & Odor \\
\hline Neurospora sp. ATCC 46892 & Fruity \\
Neurospora sp. T & Fruity \\
Neurospora africana IFO 31378 & ND $^{a}$ \\
Neurospora crassa IFO 6067 & ND \\
6068 & ND \\
6178 & ND \\
6966 & ND \\
6977 & ND \\
Neurospora sitophila IFO 4596 & Mushroom-like, fruity \\
6069 & ND \\
6070 & ND \\
Neurosporatetrasperma IFO 6982 & ND \\
\end{tabular}

a Not detectable.
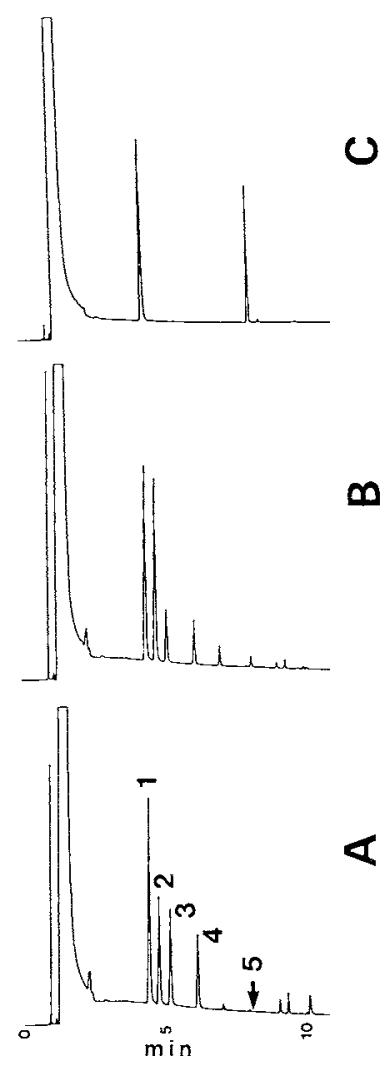

Fig. 1. Gas Chromatograms of Volatiles Produced by Neurospora Strains.

A, Neurospora sp. ATCC 46892; B, Neurospora sp. T; C, Neurospora sitophila IFO 4596.

1, methyl caproate as an internal standard; 2, isoamyl alcohol; 3, ethyl caproate; 4, acetoin; 5, unknown substance. 
Table II. Volatiles Produced by Three Neurospora STRAINS

The experimental details are given in the text.

\begin{tabular}{lcccc}
\hline & $\begin{array}{c}\text { Isoamyl } \\
\text { alcohol } \\
(\mathrm{ppm})\end{array}$ & $\begin{array}{c}\text { Ethyl } \\
\text { caproate } \\
(\mathrm{ppm})\end{array}$ & $\begin{array}{c}\text { Acetoin } \\
(\mathrm{ppm})\end{array}$ & $\begin{array}{c}\text { 1-Octen- } \\
3-\mathrm{ol} \\
(\mathrm{ppm})\end{array}$ \\
\cline { 1 - 2 } $\begin{array}{c}\text { Neurosporasp. } \\
\text { ATCC 46892 }\end{array}$ & 32.2 & 29.6 & 19.1 & $\mathrm{ND}^{a}$ \\
$\begin{array}{c}\text { Neurosporasp. } \\
\mathrm{T}\end{array}$ & 57.2 & 17.2 & 12.0 & 1.65 \\
$\begin{array}{c}\text { N. sitophila } \\
\text { IFO 4596 }\end{array}$ & $\mathrm{ND}$ & $\mathrm{ND}$ & $\mathrm{ND}$ & 20.1 \\
\end{tabular}

a Not detectable.

the same as described above.

All strains had significant growth in malt broth and as shown in Table 1, Neurospora sp. ATCC 46892, Neurospora sp. T, and $N$. sitophila IFO 4596 produced characterisic fruity or mushroom-like aromas in their culture broth, but the other strains produced no remarkable odors under these conditions. Figure I shows the gas chromatograms of the volatiles produced in cultures by the 3 odoriferous Neurospora strains and Table II shows the results of quantitative analyses of them. Strain ATCC 46892 produced about 30 ppm of ethyl caproate, which caused the fruity odor and strain $T$ produced half. They also produced significant amounts of isoamyl alcohol and acetoin. However strain IFO 4596 did not produce them; instead an unknown substance appeared at the retention time of $8 \mathrm{~min}$. This unknown substance was seen in the culture of strain $\mathrm{T}$ but not in that of strain ATCC 46892 . Because this substance was thought to be the body of the mushroom odor, we analyzed it by GC-MS. The result coincided with authentic 1-octen-3-ol (Fig. 2). GC analysis also supported this coincidence. Therefore, the unknown substance was identified as 1-octen-3-ol. GC analysis showed that it was produced in quantities of approximately $20 \mathrm{ppm}$ in the culture broth and might cause the mushroom-like odor (Table II). 1-Octen-3-ol had been discovered in an extract of Armillaria Matsutake Ito et Imai by Murahashi et al. ${ }^{4)}$ which was called "Matsutake alcohol." Isoamyl alcohol or acetoin might contribute a little to these odors.

Thus the sensory and analytical evaluations showed that these aromas were mainly caused by ethyl caproate or 1-octen-3-ol which was not produced by Neurospora sp. ATCC 46892 . Then, as judged by the production of these volatiles having characteristic odors in the malt broth, there were at least three kinds of odoriferous Neurospora strains. That is, those with the production of only ethyl caproate, both ethyl caproate and 1-octen-3-ol, and mainly 1-octen-3-ol respectively. However, strain IFO 4596

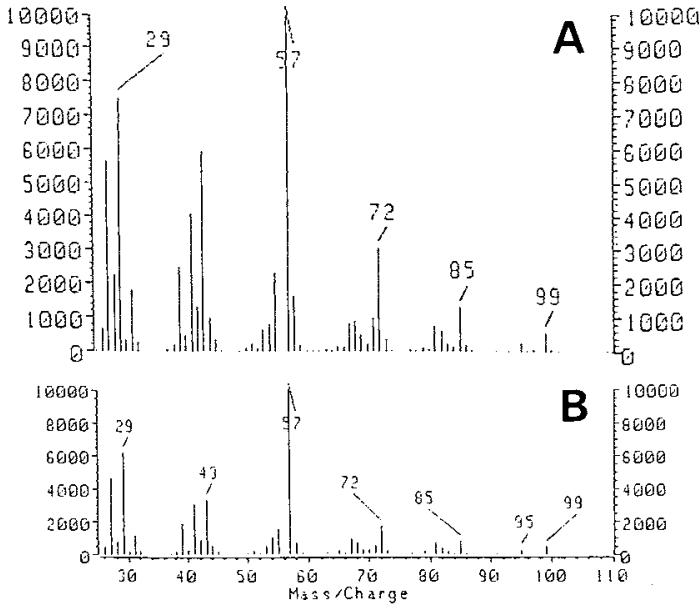

Fig. 2. GC-MS Spectra of the Unknown and 1-Octen3-ol.

A, authentic l-octen-3-ol; B, the unknown.

sometimes produces a little ethyl caproate and $N$. sitophila IFO 6070 and N. tetrasperma IFO 6982 rarely produce weak aromas. $^{3)}$

It was reported that 1-octen-3-ol was contained in some kinds of mushrooms ${ }^{5)}$ and was produced by various fungi in solid agar media. ${ }^{6)}$ To our knowledge, no reports have dealt with the production in liquid cultures by microorganisms like Neurospora. The considerable production of 1 -octen-3-ol in liquid cultures by these Neurospora strains is noteworthy.

Acknowledgment. The authors are indebted to Dr. Satoh of the Laboratory of Universidade Estadual de Campinas, Faculdade de Engenharia de Alimentos (UNICAMP), for kindly providing Neurospora sp. T.

\section{References}

1) K. Yoshizawa, H. Yamauchi, T. Hasuo, O. Akita and S. Hara, Agric. Biol. Chem., 52, 2129 (1988).

2) Y. K. Park, C. T. Zenin, S. Ueda, C. O. Martins and J. P. M. Neto, J. Ferment. Technol,, 60, I (1982).

3) H. Yamauchi, T. Hasuo, T. Amachi, O. Akita, S. Hara and K. Yoshizawa, Agric. Biol. Chem., 53, 821 (1989)

4) S. Murahashi, Bull. Inst. Phys. Chem. Res., 15, 1186 (1936).

5) H. Kameoka and M. Higuchi, Nippon Nōgeikagaku Kaishi, 50, 185 (1976).

6) M. Saito, T. Yamanishi and O. Tsuruta, Rept. Natl. Food Res. Inst., No. 34, 67 (1979). 